\title{
A imagem historiográfica de Hugo de Cluny em Leão (séc. XI-XII)
}

\author{
The historiographic image of Hugo de Cluny in León (XIth-XIIth centuries)
}

\author{
Maria Filomena Pinto Da Costa Coelho* \\ Universidade de Brasilia (UnB), Brasília, DF, Brasil
}

\begin{abstract}
RESUMO: A presença de Cluny na Península Ibérica adquiriu uma importância extraordinária entre os séculos XI e XII, na medida em que sua marca identitária transcendeu aquilo que hoje classificaríamos como domínio religioso, para alcançar o cerne da política. Especialmente no reino de Leão, o cenário cluniacense conta com atores políticos, cujos nomes são amplamente conhecidos e de grande envergadura. Embora em cada reinado a relação com Cluny se caracterize politicamente com nuances específicas, para a historiografia, é durante o governo de Alfonso VI que a presença cluniacense assume conotações políticas mais pronunciadas, por meio, principalmente, do abade Hugo de Semur. Para a historiografia em geral existem três momentos emblemáticos que evidenciariam a força política que o abade Hugo alcançou no reinado de Alfonso VI: a) o casamento do monarca com Constança da Borgonha, e das infantas Urraca e Teresa com Raimundo e Henrique da Borgonha; b) o pacto sucessório firmado por Raimundo e Henrique da Borgonha; c) o pagamento do censo a Cluny. Tentaremos, a seguir, apresentar algumas consideraçôes que nos permitam delinear a problemática que, do ponto de vista historiográfico, configura as bases que sustentam a síntese narrativa sobre esses três momentos, que foram transformados em fatos históricos.
\end{abstract}

PALAVRAS-CHAVE: Reino de Leão. Cluny. Alfonso VI. Redes Aristocráticas Medievais.

\begin{abstract}
The presence of Cluny in the Iberian Peninsula achieved an extraordinary importance in the XIth and XIIth centuries, as far as its identity mark transcended what we would classify today as religious domain, to reach the central field of politics. Specially in the kingdom of León the cluniac scenario has powerful and well known political actors. Even though the relationship with Cluny had different characteristics that depend on the historical circumstances of each kingdom, for historiography it was on the time of Alfonso VI that the presence of Cluny appeared with stronger political connotations, mainly by virtue of Hugo de Semur. In general, for historiography there are three emblematic moments that reveal the political strength that abbot Hugo achieved in Alfonso's VI kingdom: a) the monarch's marriage with Constance of Burgundy and the marriages of his daughters, Urraca and Teresa with Raymond and Henry of Burgundy; b) the "succession pact" between Raymond and Henry of Burgundy; c) the payment of a census to Cluny. Our goal is to present some problems in order to understand how historiography interprets those moments and transforms them in historical facts.
\end{abstract}

KEYWORDS: Kingdom of León. Cluny. Alfonso VI. Medieval Aristocratic Networks.

\footnotetext{
* Professora Associada do Departamento de História e do Programa de Pós-Graduação em História da Universidade de Brasília (UnB), Brasília, DF, Brasil. Doutora em História Medieval pela Universidad Complutense de Madrid. E-mail: mariafilomenadacostacoelho@gmail.com
} 
Na história da Península Ibérica, a atuação da Igreja é frequentemente encarada como a de uma espécie de organismo internacional, cujos interesses de caráter institucional/universal estariam acima das redes de poder laicas. Nessa perspectiva, tanto a decisão régia como a nobiliárquica, em acolher a ordem de Cister, em meados do século XII, apontam para uma manobra instrumental que objetivava se livrar de uma poderosa instituição - Cluny - que "oprimia”, do exterior, os reinos da Península. Ao mesmo tempo, sugere-se que, uma vez diminuído o poder dos cluniacenses, a "reforma eclesiástica" poderia ser levada a cabo a partir do interior da Península. Ela deixaria de ser uma agenda política do papado - portanto, externa - para tornar-se autóctone. Tal interpretação reforça um caráter de superioridade institucional de Cluny, que se manifestaria na forma como o grande centro monástico teria conseguido, sobretudo na segunda metade do século XI, controlar suas filiais, mas principalmente se imiscuir com o protagonismo no cenário político ibérico, diferentemente de Cister, que embora se constituísse sob a mesma dinâmica, exercera o poder de uma maneira menos "monopolista” e menos “imperialista”. Mas, tampouco se deve deixar de notar que, na ótica dos estudos sobre a monarquia, essa interpretação ajuda a sedimentar a ideia de que, a partir da segunda metade do século XII, ir-se-ia consolidando a soberania do monarca sobre o reino, que, de forma crescente, eclipsaria a autonomia de outras instituiçóes e poderes. Enfim, ao analisarmos todos os elementos da equação, percebe-se que os raciocínios de matriz institucionalista acabam por não considerar o peso incontornável das redes no fortalecimento das próprias instituições e da necessária interrelação entre essas instâncias de poder.

Nossa proposta, neste artigo, é retomar algumas das linhas interpretativas que a tradição historiográfica consagrou, bem como estudos mais recentes que a têm questionado e oferecido explicações alternativas. Segundo a perspectiva que o historiador adote, a construção do problema oferece diferentes desenhos e, é nesse sentido que desejamos contribuir para projetar sobre o passado um olhar que valorize positivamente as arestas que a pesquisa documental acaba por apresentar, incorporando-as à interpretação, ao invés de tentar disfarçá-las para não perturbarem o panorama que se pretende pintar. Também como resultado dessa intenção, assumimos como desafio tentar oferecer explicações que não fatiem a história de acordo com tipologias documentais e/ou especialidades historiográficas que terminam por incorrer em anacronismos.

A lente de observação que assumimos como ponto de partida é o da aristocracia cristã, o que nos obriga a considerar, de maneira sincrônica, grupos sociais que muitas vezes são analisados de forma separada, como laicos e eclesiásticos, assim como instituições, a exemplo da monarquia, do monacato e do episcopado. Tal abrangência permite visualizar as intensas dinâmicas políticas que configuram e reconfiguram as redes de poder, as quais, finalmente, são responsáveis, por meio de seus discursos e ações, pelo fortalecimento e/ou enfraquecimento das instituições. Assim se desenha o problema que nos move neste trabalho e que decidimos localizar entre os séculos XI e XII, no cenário político do reino de Leão, por considerar que nesse tempo e espaço há uma série de acontecimentos que nos permitem refletir de forma complexa sobre a problemática apresentada, e que foram sendo fortemente redimensionados pela historiografia ao longo dos séculos. Por se tratar de um trabalho de pesquisa ainda em desenvolvimento, neste artigo daremos conta apenas de alguns aspectos que surgiram do desdobramento do problema central, com relação à presença e atuação da Ordem de Cluny no reino leonês, e aprofundaremos as questôes relativas à Ordem de Cister em outro trabalho, que esperamos publicar em breve. 
Ao examinar o conjunto da vasta historiografia dedicada ao estudo de Cluny na Península Ibérica é fácil identificar algumas das principais etiquetas, por meio das quais tradicionalmente se explica o porquê dos monges borgonheses terem cruzado os Pireneus: as guerras de Reconquista e a Reforma Romana. Embora os dois motivos possam entrelaçar-se com frequência, percebe-se, no entanto, que de acordo com a situação a ser explicada pelo historiador, a ênfase incide mais, ora na espiritualidade que a aristocracia cristã transpirenaica levava para a Península juntamente com a ajuda militar que oferecia aos monarcas ibéricos, ora na força do projeto de reforma da cristandade emanado do papado, de quem Cluny seria a ponta de lança. No primeiro caso, o modelo monástico cluniacense, devido ao êxito que alcançara com sua rede de filiais e aos laços familiares que o uniam às principais casas nobiliárquicas da França, ter-se-ia difundido também em Leão como parte indissociável do modo de vida aristocrático. Como veremos, também a monarquia terá um papel importante ao promover novas fundaçóes, reformar antigas igrejas e mosteiros, além de manter um fluxo importante de doações pias a casas monásticas sob patronato da nobreza. Com relação à Reforma Romana, embora se destaquem centros monásticos filiados a Cluny como motores da transformação dos costumes exigida pelo papado, o peso maior acaba por recair nos vários bispos de origem francesa que assentaram cátedra na Península, com o devido destaque para os vínculos que de alguma forma os ligavam à abadia borgonhesa.

Mas há uma certeza que praticamente une a historiografia: a presença de Cluny na Península Ibérica adquiriu uma importância extraordinária entre os séculos XI e XII, na medida em que sua marca identitária transcendeu aquilo que hoje classificaríamos como domínio religioso, para alcançar o cerne da política. Especialmente no reino de Leão, o cenário cluniacense conta com atores políticos, cujos nomes são amplamente conhecidos e de grande envergadura, a começar pelos monarcas, Fernando Magno, Alfonso VI, Urraca, Alfonso VII, passando pelos abades de Cluny, entre os quais se destaca obviamente Hugo de Semur - o Grande -, uma dezena de eclesiásticos importantes que ocuparam sés episcopais e/ou exerceram atividades legatinas, como Roberto de Sahagún, Bernardo de Toledo, Geraldo de Braga, Maurício Burdino, Jérôme Geret, Diego Gelmírez, Ricardo de São Vitor de Marselha, e membros destacados da nobreza, como Raimundo e Henrique da Borgonha. Embora, em cada reinado dos monarcas citados, a relação com Cluny se caracterize politicamente com nuances específicas, para a historiografia, é durante o governo de Alfonso VI que a presença cluniacense assume conotações políticas mais pronunciadas. Como veremos adiante, as conclusões dos historiadores oscilam entre o protagonismo atribuído ao monarca e ao abade de Cluny, no intuito de explicar a quem caberia a autoria do projeto de instalar em Leão essa rede aristocrática borgonhesa, de grande sucesso. Se por um lado há hipóteses que se inclinam por atribuir a Alfonso VI a decisão de abrir o reino à onda "civilizatória” que os borgonheses podiam oferecer por meio da organização jurídica e cerimonial da vida eclesiástica, com vistas ao próprio fortalecimento monárquico ${ }^{1}$, por outro, existem interpretações que apontam para um plano da aristocracia borgonhesa que, a partir da abadia de Cluny, se expandia e colonizava reinos ibéricos, entre os quais, Leão (DEFOURNEAUX, 1949; HENRIET, 2000). Entretanto, é ainda preciso acrescentar às duas hipóteses a Reforma Romana, cujo papel, para os historiadores, ganha contornos específicos, mas sempre como instrumento político que identifica aqueles que aderiam ao partido cluniacense e ao monarca. A adoção do ritual romano, para Claudio Sánchez-Albornoz, adquire significados que acabam por reunir as tendências que acabamos de apontar: 
León y Castilla, sintiendo doblada la gravedad del peligro por su aislamiento en el Finis terrae que ocupaban, se vieron forzados a buscar con ansiedad dramática, allende al Pirineo, la apoyatura cultural indispensable para poder defenderse del amenazador contagio de los valores espirituales hispano-musulmanes (SÁNCHEZ-ALBORNOZ, 1962, p. 604-605).

Neste ponto, faz-se necessário introduzir um fator complicador presente nas interpretaçóes mais tradicionais, ou seja, naquelas que tendem a apresentar panoramas políticos homogêneos, nos quais os atores agem - ou deveriam agir - de acordo a padrões institucionais mais próximos de nossa contemporaneidade, e que passaremos a chamar padrões institucionalistas. Isso é sobretudo visível no que se refere à monarquia, ao papado e a Cluny, aos quais se atribuem agendas próprias, com conteúdos bem definidos - verdadeiros projetos - que servirão aos historiadores como medidas a partir das quais se interpretam as circunstâncias e os fatos. Tal metodologia permite criar cenários homogêneos e previsíveis, que possibilitam avaliar de maneira positiva ou negativa os movimentos dos atores políticos, atribuindo-lhes, inclusive, capacidades de projetar e antecipar lances de grande efeito dentro de arcos temporais bastante amplos.

Entretanto, à luz da documentação disponível para o Reino de Leão, na época de Alfonso VI, não parece possível definir com segurança os conteúdos do "projeto" da monarquia com relação a Cluny; do "projeto" de Cluny para Leão; e, muito menos, do que seria o "projeto” de Roma. Para além de ideias muito gerais que os discursos dessas instituições difundiam, as circunstâncias políticas transformavam esses "princípios" numa miríade de enunciados e possibilidades de ação, que os historiadores tendem a domesticar para caberem no truísmo que a tradição historiográfica consagrou. Assim, como em outras temáticas, o comportamento dos atores é julgado à luz de "um projeto", em termos de seu cumprimento ou descumprimento. Ainda no que se refere à documentação, há uma questão amplamente conhecida, mas pouco considerada: a fiabilidade. ${ }^{2}$ As informações de que dispomos com relação ao problema que pretendemos enfrentar são oriundas de documentos cuja datação apresenta muitas dúvidas, e/ou revelam claros sinais de terem sofrido interpolaçóes, e/ou podem ser falsificaçóes, e/ou foram produzidos posteriormente aos acontecimentos, como no caso das crônicas ou das compilaçóes documentais da Idade Moderna, cujos originais copiados desapareceram. Sem pretendermos solucionar os aspectos atinentes ao aparato erudito que tais conclusões requerem, e que têm sido objeto de estudiosos dedicados e competentes, nossa intenção, porém, é tentar incorporar essas dúvidas à análise que nos propomos a realizar.

Para a historiografia em geral, existem três momentos emblemáticos que evidenciariam a força política que Cluny alcançou no reinado de Alfonso VI: a) o casamento do monarca com Constança da Borgonha, e das infantas Urraca e Teresa com Raimundo e Henrique da Borgonha; b) o pacto sucessório firmado por Raimundo e Henrique da Borgonha; e, c) o pagamento do censo a Cluny. Tentaremos, a seguir, apresentar algumas consideraçóes que nos permitam delinear a problemática que, do ponto de vista historiográfico, configura as bases que sustentam a síntese narrativa que se estende da literatura escolar à acadêmica, para descobrirmos "como sabemos o que sabemos" sobre esses três momentos, que foram transformados em fatos históricos. Mas, antes, começaremos por considerar alguns aspectos sobre a chegada dos cluniacenses ao reino de Leão. 


\section{Cluny em Leão}

Os laços entre Cluny e o reino de Leão, no que se refere à vida monástica, ter-se-iam iniciado, em $1073^{3}$, com a doação que Alfonso VI fez ao abade Hugo de Semur, do mosteiro de S. Isidro de Dueñas, em Tierra de Campos (REGLERO DE LA FUENTE, 2008). Nessa mesma região, localizam-se os mosteiros que nos anos seguintes seriam igualmente objeto de doação a Cluny, ou que teriam adotado os costumes cluniacenses: Santiago de Astudillo, San Juan de Hermédes de Cerrato e Sahagún. Na esteira dessas doações régias, registram-se também doaçôes feitas por importantes linhagens a Cluny, como no caso da entrega do mosteiro de San Zoilo de Carrión, pelos Banu-Gómez, ou simplesmente de bens e direitos, como fizeram os Banu-Alfonso.

A escolha de uma data para marcar a entrada de Cluny no reino de Leão constitui um problema, uma vez que a presença da abadia borgonhesa antecede esse vínculo institucional que caracterizaria juridicamente - para alguns de forma apropriada - o início da relação, ou seja, a doação de um mosteiro à Ordem. Entretanto, se à perspectiva institucionalista do monacato acrescentarmos outras instâncias de atuação política, próprias da natureza elástica e plural das instituições da plena Idade Média (COELHO, 2018), será difícil decretar uma data precisa para o início dessa relação.

Primeiro, é preciso decidir se o historiador deve apenas entender como dignas de consideração as datas que assinalam os vínculos estabelecidos entre a cabeça política do reino (o monarca) e a cabeça política da ordem (o abade). Em segundo lugar, se tais vínculos devem refletir unicamente aquilo que se refere à jurisdição monástica. De forma breve, queremos apontar a necessidade de, por meio do alargamento das tipologias documentais, diminuir o protagonismo que se tem atribuído às cabeças políticas, frequentemente entendidas como motores exclusivos da entrada de Cluny em Leão. No caso de Alfonso VI, especificamente, chega-se mesmo a interpretar as doações que as linhagens do reino oferecem a Cluny, ou a suas filiais, como adesão à política régia de aproximação - para alguns, submissão - à abadia borgonhesa. Estudos monográficos, entretanto, comprovam que a presença cluniacense é anterior aos vínculos jurídicos que se estabelecem entre casas monásticas leonesas e Cluny, evidenciada pela difusão do modo de vida beneditino propagado pela aristocracia da Borgonha, por meio de suas redes e dos laços que ela vai construindo e espraiando ao longo do século XI. Fundem-se, de maneira difícil de deslindar, as vias espirituais, militares, familiares, que serviram como canais de difusão cluniacense. ${ }^{4}$ Por outro lado, a dimensão política, que não pode ser entendida separadamente da religião, permite constatar os vínculos de Leão com Cluny antes de 1073, data da doação de S. Isidro de Dueñas. A evidência de maior prestígio entre os historiadores é o censo que a monarquia leonesa pagava a Cluny, pelo menos desde o reinado de Fernando Magno. Mas, as notícias relativas às doações pias que Sancho, el Mayor, realizou em favor da abadia borgonhesa, atestariam que desde o início do século XI haveria uma piedade cluniacense difundida em Leão capaz de canalizar as benesses régias. Embora a tipologia documental normalmente considerada pelos historiadores sustente o protagonismo régio dessa relação, pensamos que o seu alargamento pode propiciar a inclusão de outros atores sociais, como nota Carlos Reglero, ao atribuir às linhagens da nobreza algum protagonismo, ainda que subsumido nos vínculos que as atavam à monarquia:

El destacado papel jugado por los reyes leoneses en la implantación de Cluny en España ha dejado siempre en segundo término a la nobleza. Con todo, la tercera parte de los prioratos 
hispanos fueron donados por familias de la nobleza, ligadas por lazos de fidelidad y parentesco a la monarquía (REGLERO DE LA FUENTE, 2009, p. 2).

Tal como observou há bastante tempo Charles Bishko, a penetração de Cluny na Península Ibérica ocorreu de maneira bastante irregular, mas com clara concentração nas regióes da Rioja Alta, Tierra de Campos, Galícia e Portugal, como provável resultado da "íntima aliança estabelecida entre Cluny e o Império Leonês da Hispania sob os imperadores Fernando I e Alfonso VI”. Com anterioridade, como já referido, poder-se-ia comprovar a penetração da regra beneditina e/ou dos costumes beneditinos em algumas casas monásticas, muito embora para José Andrade isto seja bastante difícil de mapear, por exemplo, para as áreas da Galícia e de Portugal (ANDRADE, 2017, p. 220). ${ }^{6}$ De toda forma, a "ideia de uma Ibéria do oeste solidamente cluniacense" deve-se à maneira ampla como se considera o fenômeno, sem restringi-lo, obviamente, aos estabelecimentos monásticos:

Tal ponto de vista considerou a mudança dos rituais litúrgicos e as pretensóes da própria reforma Gregoriana, o sistema de escrita, a chegada do Românico e a emergência de uma verdadeira rota de peregrinação francesa para Compostela como mudanças importadas e implantadas pelos franceses. Imaginou-se também a abrangente influência de Cluny como principal motor de todas essas transformaçôes (ANDRADE, 2017, p. 221-222).7

O fato é que se nos ativermos apenas às fundações propriamente monásticas e seus vínculos jurisdicionais com Cluny, ou com algumas de suas filiais transpirenaicas, o panorama não é animador, levando Ermelindo Portela a pintá-lo de cinza e a José Andrade de fainting black, em clara alusão à fraca presença dos monges do hábito preto no extremo oeste da Península (ANDRADE, 2017, p. 222). Os números são um problema, principalmente porque é necessário decidir se se consideram somente os casos de sucesso de reforma e/ou de fundação cluniacense, ou se também se contabilizam as tentativas que fracassaram, além daquelas que se limitaram a adotar os costumes cluniacenses, mas sem estabelecerem vínculos de dependência formal. ${ }^{8}$ Para José Andrade, não há dúvida que a tradição historiográfica tendeu a exagerar os números, e considera que dos 16 priorados cluniacenses na província da Hispania, a Galícia contava com $1 / 4$ das casas monásticas e Portugal apenas com 1/8 (ANDRADE, 2017, p. 223). Entretanto, apesar da baixíssima densidade monástica "não seria exagerado afirmar que a influência política da Borgonha e de Cluny foi mais profundamente sentida na Galícia e em Portugal do que em qualquer outro reino ibérico" (ANDRADE, 2017, p, 225). A magnitude da presença de Cluny, portanto, não se mede pelo número de priorados, mas por uma presença eclesiástica e política que, paradoxalmente, prescinde de seu elemento identitário essencial, o mosteiro. Em vez disso, Cluny se afiança por meio da forte presença de monges oriundos de redes aristocráticas cluniacenses, basicamente borgonhesas e aquitanas, mas que em Leão assumirão a dignidade episcopal, convertendo-os em lideranças cujo alcance político se estenderá da Península Ibérica à Roma, passando, naturalmente, pela França.

Como tentaremos mostrar, a presença de Cluny no reino de Leão foi tratada pela historiografia quase sempre por meio dos personagens que se identificavam - ou foram identificados pelos historiadores - com a Ordem, mas também por meio das missóes que se lhe atribuem nos planos político e militar: a Reforma Romana e a Reconquista. $\mathrm{O}$ vocabulário que costuma dar corpo às narrativas recorre a palavras altissonantes, como interferência, ingerência, intervenção, intercessão, 
modernização, civilização, romanização, institucionalização... Portanto, a depender daquilo que se pretenda valorizar, não há meias medidas: positivas ou negativas. Para Oliveira Marques, “a intervenção dos cluniacenses nos assuntos político-militares da Hispania tem sido, desde há muito, acentuada, embora não convenha exagerá-la, como alguns autores fazem” (MARQUES, 1996, p. 14). Neste caso, o cuidado revela temor quanto às implicaçóes que, para uma perspectiva mais nacionalista e eclesiástica, supõe admitir que um braço da igreja, apesar de seus princípios beneditinos de virtude e afastamento das questóes mundanas, não somente se imiscuísse na alta política como modificasse os rumos e a configuração geopolítica dos reinos cristãos.

No caso de Portugal, poder-se-ia mesmo pensar que a independência do reino faria parte do "projeto" político da expansão e consolidação de Cluny na Península Ibérica. Assim o entendia Vieira de Castro: "da alta visão política de Cluny, tendo ao seu serviço um agente de excepcionais qualidades como o Conde D. Henrique, é que nasceu Portugal” (CASTRO, 1938, p. 37). Mas também era possível que a atuação do mosteiro borgonhês estivesse a serviço de uma agenda nacional francesa, que pretendia a fragmentação da Península, impedindo assim o renascimento do império hispânico. Mas, de acordo com o Pe. Avelino Costa, além de não ser possível comprovar documentalmente tal pretensão, "a política, como tal, era alheia ao espírito de Cluny. Os seus monges defendiam os interesses religiosos das terras onde se encontravam, como se dela fossem naturais e não para favorecerem a política francesa” (COSTA, 1948, p. 10). Num tom que coloca Cluny na perspectiva da universalidade que a Igreja deveria assumir, Oliveira Marques considera que

[...] questóes político-militares, religioso-eclesiásticas e de família podiam assim, eventualmente, confundir-se. Por outro lado, a concessão de feudos, de tenências e de cargos de natureza política, militar ou eclesiástica, fazia-se a 'estrangeiros', sem qualquer restrição ou repugnância. Antepassada das modernas uniões de Estados e mais flexível até do que elas, a Respublica Christiana era um espaço comum de circulação, de fixação e de nomeação de pessoas, que poucas barreiras conhecia (MARQUES, 1996, p. 15).

Os autores divergem - e muitas vezes se contradizem - ao avaliarem o papel dos monges borgonheses. Recorrendo ainda a Vieira de Castro, "a influência de Cluny fêz-se sentir em todos os campos e não houve país onde se manifestasse tão decisivamente como na Espanha" (CASTRO, 1938, p. 37). E para Justo Pérez de Urbel, "cluniacenses foram donos dos mosteiros, dos bispados e até da corte de Alfonso VI” (PÉREZ DE URBEL, 1935, p. 177).

Assim, se os motivos que levaram os monges da Borgonha a se instalarem no reino de Leão podem não estar claros, ou simplesmente terem explicações variadas, a sua presença, bastante documentada, requer a ampliação do significado que Cluny adquiriu no cenário leonês, que alarga bastante o conceito pelo qual o medievalismo circunscreve as ordens monásticas beneditinas da Idade Média. Tal panorama possibilita ao historiador um bom exercício de interpretação, por meio do cruzamento das fontes e da própria historiografia.

\section{Cluny como rede política}

O enorme poder político que Cluny alcançou em Leão é normalmente retratado pela historiografia por meio da relação que Alfonso VI manteve com o grande abade, Hugo de Semur, ou, 
melhor, da capacidade que este demonstrou em interferir de forma vigorosa nos assuntos do reino, principalmente, ao promover uma política de casamentos que vinculava a alta nobreza borgonhesa à monarquia leonesa, de ser o artífice de um plano de divisão do reino de Leão entre Raimundo e Henrique da Borgonha, entendidos como representantes dos interesses cluniacenses, e de conseguir canalizar importantes recursos financeiros da Hispania para a sua abadia. Nas palavras do próprio abade Hugo:

De Domno Alphonso Hispaniarum Rege, nostro fideli amico, qui tanta ac tália bona nobis fecit, et adhuc indesinenter facit, ut neminem Regum vel Principum sive priscis sive modernis temporibus ei comparare possimus... (AZEVEDO, 1942, p. 31).

Haveria ainda outros aspectos que poderíamos aprofundar com o objetivo de compreender as interpretações que se fizeram ao longo do tempo sobre essa relação, mas consideramos que os três que agora propomos se constituem como verdadeiros marcos factuais para a historiografia e por isso possibilitam uma análise de conjunto. Para além desses marcos, evidentemente que os processos que envolvem a chamada Reforma Romana e as intrincadas conexões e redes promovidas pelos bispos cluniacenses são problemas igualmente importantes para compreender o todo, mas que esperamos abordar em outra oportunidade.

\section{Cluny e as alianças matrimoniais leonesas}

De forma geral, aceita-se que o casamento de Alfonso VI com Constança de Borgonha, em 1078, foi obra de Hugo de Semur. O abade era irmão de Hélia de Semur, de cuja união com Roberto, duque da Borgonha, nasceu Constança. O monarca leonês já havia sido casado anteriormente com Inês, entre 1073/4-1078, filha de Guilherme VIII, duque da Aquitânia, um enlace que para alguns autores é também interpretado como fruto do poder de influência que Cluny exercia sobre Alfonso VI(DAVID, 1947, p. 361; SALAZAR Y ACHA, 1992-1993, p. 299). O parentesco entre Inês e Constança - eram primas - e o fato de Hugo ser tio materno de Constança, leva a imaginar que tenha sido o abade a promover os casamentos com vistas a conseguir do rei de Leão um tratamento privilegiado com relação a Cluny.

Sobre as origens de Inês de Aquitânia, vejamos o que nos diz Salazar y Acha:

Aparece documentada por primera vez el 16 de junio de 1074 acompañando a su esposo el Rey, sin que las crónicas españolas nos desvelen sus orígenes familiares. Afortunadamente una noticia del Cronicón Malleacense, correspondiente al año 1069, nos revela su identidad, como hija de Guido Guillermo VIII, Duque de Aquitania, y de su mujer Matilde de la Marche. Aunque este Cronicón no nos dice el nombre de la princesa, no hay ninguna duda en identificarla con la Inés que, cinco años más tarde, aparecerá en la documentación, pues este nombre, raro en Castilla, era típico de las princesas aquitanas (SALAZAR Y ACHA, 1992-1993, p. 308-309).

Portanto, é preciso admitir que não se pode afirmar com segurança que Inês seja realmente do ducado da Aquitânia, mas, se assim a considerarmos, não há qualquer parentesco próximo entre o abade de Cluny e a rainha de Leão. Ainda dentro das conjecturas favoráveis aos supostos vínculos familiares de Inês, constatar-se-ia que ela era prima em terceiro grau da segunda mulher 
de Alfonso VI, Constança, uma vez que Guilherme III da Aquitânia era tataravô de ambas. Aliás, é justamente devido a esse longínquo parentesco que os historiadores baseiam suas conclusões, a partir de uma epístola que o papa Gregório VII dirige ao monarca, em 1080, na qual, entre outros assuntos, o acusa de illicitum connubium quod cum uxoris tuae consanguinea inisti (SALAZAR Y ACHA, 1992-1993, p. 317). Para Salazar y Acha, além de outros historiadores, o pontífice reprovava que o monarca tivesse casado com uma parente da finada rainha sem pedir as devidas dispensas. Portanto, não caberiam dúvidas quanto à identidade de Inês, embora nos pareça que a interpretação das palavras de Gregório VII permita, talvez, estabelecer outras associações que hoje nos escapam, mas que à época fossem o suficientemente claras para não ser preciso dar nomes aos faltosos.

Sobre as origens familiares de Constança, como referimos, não há dúvidas. Entretanto, existe um detalhe que não é muito citado. Quando casou com Alfonso VI, Constança era viúva do conde de Chalon-sur-Saône, Hugo II. E são justamente os laços que ela estabeleceu por meio de seu primeiro casamento que a colocam como protagonista da crônica do mosteiro de S. Philibert de Tournus, escrita pelo monge Falcon, no final do século XI, a mando do abade Pierre I (SAINT-JEAN VITUS, 2006; SENRA, 2011). Nela, o autor revela que se deve ao abade de Tournus a intermediação do enlace de Constança com o rei de Leão. O conde de Chalon era o patrono do mosteiro e, depois de sua morte, o abade Pierre ter-se-ia sentido na obrigação de encontrar um destino de prestígio para a viúva, que sempre demonstrara especial devoção pelas relíquias de $S$. Filisberto. Depois de seu casamento, e na condição de rainha de Leão, Constança manteve seus laços com o mosteiro e o abade Pierre, por meio de doações vultosas e da defesa dos interesses de Tournus. Ainda de acordo com a crônica, em 1087, depois das vitórias das tropas que cruzaram os Pirineus para auxiliar Leão contra os mouros, sob o comando da casa ducal da Borgonha, o duque Eudes I, na corte de Alfonso VI, reconheceu que havia desrespeitado os direitos dos monges, ao não permitir que eles tivessem acesso ao patrimônio que Constança lhes havia doado pela alma do primeiro marido, e registrou por escrito sua disposição de se redimir e de compensá-los (AMARAL; BARROCA, 2016, p. 38). ${ }^{\text {? }}$

No que se refere ainda ao mosteiro de Tournus, é necessário lembrar que suas relações com Cluny são conflitivas desde a fundação. Ambos os mosteiros compartilham território na região do Mâconais, gerando uma convivência difícil com permanentes disputas, por meio das quais os abades Pierre e Hugo medem forças. Como contraponto, Tournus se apoia nos bispos de Chalon e de Mâcon e, principalmente, no papado (SAINT-JEAN VITUS, 2006, p. 86-87). Este xadrez político pode ser importante para compreender alguns lances dos partidários de Cluny no reino de Leão, especialmente em Sahagún, nas disputas que envolvem os atores identificados com o papado e a Reforma.

Com base nestas breves considerações sobre os casamentos de Alfonso VI, pensamos que não se pode afirmar com segurança que Hugo de Cluny tivesse planejado, ou de alguma forma influenciado, na escolha de Inês e de Constança, com vistas a canalizar benefícios para a ordem. Claro que tampouco se pode dizer o contrário, uma vez que a versão da crônica de Tournus, que atribui a Pierre a autoria das tratativas do casamento do rei leonês com Constança, pode falsificar a verdade com vistas a promover o abade, atribuindo-lhe capacidades políticas que chegam à Península Ibérica, para colocá-lo no mesmo patamar de seu arquirrival, Hugo de Semur. Mas, em favor da versão da crônica talvez pudéssemos acrescentar as conclusões a que chega Luís Senra, sobre as 
claras influências arquitetônicas de S. Philibert de Tournus que se constatam em Sahagún, de final do século XI, mostrando que o abade Pierre também chegou a Leão, muito embora tivesse sido eclipsado posteriormente pela força da narrativa de Cluny que o venceu, pelo menos, no campo da memória (SENRA, 2011).

Os outros casamentos atribuídos à influência de Hugo são os de Raimundo e Henrique da Borgonha com Urraca e Teresa, filhas de Alfonso VI. Embora tradicionalmente os condes sejam referidos como borgonheses e primos, dando a sensação de serem oriundos da mesma família e rede de interesses, na verdade trata-se de uma situação bastante diferente. Raimundo era filho de Guilherme I (Tête Hardie), conde da Borgonha, o que o colocava na esfera de influência do imperador Henrique IV; o condado da Borgonha era palatino. Já Henrique, de acordo com a tradição, era filho do duque da Borgonha, Henrique (Damoiseau), cujas ligações familiares o vinculavam à dinastia dos Capetos, portanto, ao rei da França. Apesar das circunstâncias da grande política terem colocado os dois ramos linhagísticos em campos opostos, também se constata que o fato de compartilharem uma geografia comum levou a que estabelecessem laços, como no caso de Guy II Mâcon e de Hugo I que renunciaram, respectivamente, ao condado e ao ducado da Borgonha, para tomarem o hábito no mosteiro de Cluny, ou como se comprova pelo casamento de Sibila, irmã de Raimundo, com Eudes I, irmão de Henrique. Aliás, é esse o elo familiar que uniria os genros de Alfonso VI; não são primos próximos, como se costuma afirmar, mas contraparentes (AMARAL; BARROCA, 2016, p. 50-51). ${ }^{10}$

Porém, uma vez mais, entramos no campo das incertezas factuais, uma vez que a identificação de Henrique, como membro da casa ducal borgonhesa não é segura. Nesse sentido, se ele não for filho de Henrique Damoiseau, desapareceria o estranhamento que a historiografia costuma manifestar sobre a decisão de Alfonso VI de casar Urraca, sua filha legítima, com Raimundo, do ramo condal da Borgonha, e de reservar à Teresa, fruto de uma relação ilegítima, um casamento com a casa ducal, portanto, de categoria social superior. De todo modo, haveria que pensar que Henrique certamente seria descendente de um ramo importante da nobreza de além-Pirineus.

Mas, para o tema que nos ocupa, devemos sublinhar que atribuir a Hugo de Semur a decisão estratégica de arranjar os casamentos de Raimundo e de Henrique com as filhas de Alfonso VI, devido aos laços familiares que supostamente o atavam aos dois cavaleiros, para assim poder levar a cabo seu projeto de poder no reino de Leão, não encontra lastro seguro na documentação. Lembremos que, se pode haver dúvidas razoáveis quanto ao grau de parentesco com Henrique - de quem poderia ser tio-avô -, no que se refere a Raimundo não se comprovam laços familiares próximos.

A decisão de Alfonso VI de casar Urraca com Raimundo é frequentemente explicada no contexto da ajuda militar da nobreza da Borgonha que, em 1087, cruzou os Pirineus, como já referimos. Para tentar superar o fracasso frente às tropas muçulmanas de 1086, em Zalaca (Sagrajas), o monarca pediu a ajuda de Eudes I, que organizou um exército formado por outros nobres importantes, entre os quais se destacam seu irmão Roberto, o conde de Toulouse, Raimundo de Saint Gilles, e Hugo de Lusignan (MARQUES, 1996, p. 15-16). Raimundo também fazia parte desse séquito, o que nos leva a uma vez mais chamar a atenção para a convivência e o eventual compartilhamento de interesses entre os partidos palatino e capetiano da Borgonha. Para boa parte dos historiadores, foi nesse contexto que Alfonso VI conheceu Raimundo e se decidiu pelo enlace. O casamento ocorreria em 1090-1091.

No que se refere ao casamento de Henrique com Teresa, as dúvidas são maiores, pois não se sabe com certeza quando é que o futuro conde de Portugal chegou por primeira vez à corte leonesa. 
Para Oliveira Marques, por exemplo, Henrique acompanhou Raimundo para a celebração de seu casamento com Urraca (MARQUES, 1996, p. 16). Luís Carlos Amaral e Mário Barroca, mais recentemente, inclinam-se pela tradição que afirma que a entrada de Henrique da Borgonha na Península se deu com anterioridade, por ocasião da expedição comandada por Eudes. Mas, o fato é que, tal como os autores admitem, não há menções a Henrique nos registros documentais da Borgonha ou de Leão e Castela até o seu casamento com Teresa (AMARAL; BARROCA, 2016, p. 67). Portanto, tudo são conjecturas.

A memória dos séculos seguintes explica-nos as razóes que levaram Alfonso VI a casar Teresa com Henrique, de acordo com os tempos e a cultura política, como destaca a Crónica General de España, de 1344:

[...] a primeira, por que este conde era muy fidalgo e de grande sangue, ca era primo coyrmaão do conde dom Reymố de Tollosa e veera cô ele de sua terra por ho honrarar em seu casamento e por fazer romaria a Santiago; e a outra, por que era o melhor homem d'armas per seu corpo que se podia saber (apud AMARAL; BARROCA, 2016, p. 38).

As cópias que se conhecem da crônica datam do século XV, pelo qual podemos apenas dizer que, nesse século, o motivo da ida de Henrique para Leão era para acompanhar Raimundo e peregrinar a Santiago. Assim, se as motivações estavam originalmente ligadas aos planos do abade de Cluny, o fato é que elas não ficaram na memória, coisa que se poderia explicar evidentemente por vários fatores, entre os quais, a necessidade de apagar uma interferência "estrangeira” na história do reino.

Porém, há uma evidência documental famosa que atestaria a forte influência que Hugo de Semur exercera sobre Raimundo e Henrique da Borgonha e que, de forma retroativa, costuma embasar as conclusóes dos historiadores nesse sentido. Trata-se do Pacto Sucessório, do qual trataremos a seguir.

\section{Cluny e a sucessão ao trono leonês}

De forma resumida, o Pacto Sucessório é o instrumento pelo qual Raimundo, já instituído como conde da Galícia, e Henrique estabelecem as condiçóes para a futura sucessão de Alfonso VI, por meio da repartição do território do reino e de riquezas vultuosas, como o tesouro de Toledo. O pacto teria sido concebido por Hugo de Cluny, tal como se pode ler claramente no endereçamento da carta que transcreve o documento:

Ao senhor e reverendíssimo abade de Cluny, Hugo, e a toda a congregação de S. Pedro, o conde Raimundo, o seu filho e o conde Henrique, seu vassalo, desejam saúde e amor em Cristo. Ficai a saber, caríssimo Padre, que, depois devermos o vosso legado, pelo temor de Deus omnipotente e do bem-aventurado apóstolo Pedro e pela reverência da vossa dignidade, o que nos mandastes fazer nós o fizemos na mão do senhor Dalmácio Geret (ESTEFÂNIO, 2011, p. 13). ${ }^{11}$

$\mathrm{Na}$ avaliação de Pierre David, Hugo de Cluny, diante da real possibilidade de que o rei Alfonso VI passasse o trono para o filho que tivera de sua relação ilegítima com Zaida, viúva do rei da taifa de Córdoba, e de que isso "prejudicasse os interesses da cristandade na Espanha”, entendeu que 
Raimundo e Henrique deveriam agir de comum acordo para impedir tal desenlace(DAVID, 1948, p. 277). ${ }^{12}$ Em termos estratégicos, pelo texto, a primeira operação refere-se à tomada de Toledo e à preservação de dois terços do tesouro para Raimundo. $\mathrm{O}$ território da jurisdição de Toledo será entregue a Henrique, o qual deverá prestar homenagem a Raimundo, relativamente a esse domínio. Mas, caso Raimundo não pudesse entregar Toledo a Henrique, então este deveria ajudá-lo a conseguir Leão e Castela, em troca da Galícia. Pierre David conclui, ainda, com base em outras fontes, que Raimundo se considera com direito à sucessão de Alfonso VI, pois este assim o teria prometido por juramento (DAVID, 1948, p. 277-278)..$^{13}$

Além do claro endereçamento do instrumento jurídico, que atesta que Raimundo e Henrique dividirão o império de Alfonso VI para obedecer à vontade de Hugo de Cluny, alguns historiadores reforçam tais evidências por meio do cruzamento com outras fontes que evidenciam o sistemático favorecimento da ordem, como demonstraria a generosa doação de terras e direitos que Henrique fez ao mosteiro de S. Isidro de Dueñas, em 1105, como parte de uma estratégia para "alcançar as boas graças do clero e da nobreza leoneses para os seus propósitos expansionistas” (MARQUES, 1996, p. 20, nota 25; BISHKO, 1970). Tal argumento, entretanto, não parece se enquadrar na lógica que presidiria a doação a um mosteiro que pertencia, justamente, à órbita de Cluny.

O conteúdo do Pacto prestou-se a muita discussão entre os historiadores, animados pelas prováveis implicaçôes que tal instrumento teria na época em que foi produzido, que vão desde a óbvia traição ao sogro por parte dos genros - coisa que mancha a fama dos condes -, à ingerência “imperialista” do abade de Cluny. Mas, uma das implicações que mais animou as discussões entre a historiografia portuguesa e espanhola diz respeito ao tom de subordinação de Henrique com relação a Raimundo, uma situação jurídica delicada na perspectiva das origens da independência de Portugal. A classificação jurídica do instrumento ganha especial destaque e oscila entre pacto de vassalagem e pacto de amizade e segurança, com as diferentes consequências que daí se deduzem.

Outro aspecto importante, que animou as discussões, refere-se à datação, um enigma que os estudiosos tentam resolver por meio das principais referências aludidas no texto. Certamente, Toledo ocupa um lugar de destaque, e o fato de Raimundo e Henrique prometerem dividir o tesouro da cidade, em tom de repartição de botim, levou alguns a propor uma data anterior a 1085, portanto, antes de sua reconquista. Mas, isso esbarraria com outros problemas cronológicos difíceis de resolver, como o das datas em que Sancho, filho da moura Zaida, havia sido declarado sucessor, fato crucial que, na argumentação de alguns historiadores, explicaria a existência do Pacto. Isso poderia sugerir tratar-se de um documento produzido por volta de 1105 . Há ainda vários elementos que suscitam dúvidas e polêmicas e que, dadas as contradiçôes da própria narrativa, alimentam debates eruditos e, sobretudo, requerem esforços contorcionistas e imaginativos para enquadrar o texto no contexto político desejado.

Toda essa incerteza decorre da ausência de uma data escrita no documento, mas, sobretudo, da possibilidade que o manuscrito fosse falso, uma vez que se acreditava, até recentemente, que o único texto do Pacto Sucessório se encontrava copiado por Luc d’Achery, no século XVII, em seu famoso Spicilegium. Tal problema foi objeto de um artigo publicado por Abel Estefânio, em 2011, no qual defendia justamente tratar-se de uma falsificação, mas a continuação da pesquisa lhe permitiu encontrar evidências mais seguras que o levaram a admitir a autenticidade do Pacto Sucessório (ESTEFÂNIO, 2011; 2014). Neste novo estudo, Estefânio propõe uma data para a realização do pacto que estaria de acordo com um fato importante, no que se refere aos destinos 
da sucessão do trono de Leão: o nascimento do filho de Raimundo e Urraca, Alfonso Raimúndez, em 1105. De acordo com o autor, é possível que o aparecimento de um descendente varão de Raimundo tenha levado o abade Hugo de Cluny a vislumbrar a possibilidade concreta de catapultar a influência da rede borgonhesa até o trono leonês, afastando um provável sucessor inadequado, como era Sancho Alfonsez.

Ao se considerar o teor do documento como fidedigno, ${ }^{14}$ trata-se de uma evidência incontornável que deve nos levar a entender as vantagens de adotarmos a perspectiva de redes e de considerarmos os atores que se movem entre suas malhas como pertencentes a uma aristocracia cristã, de modo a superarmos os reducionismos que a divisão entre papeis sociais laicos e eclesiásticos pode gerar.

\section{Cluny e o censo de Leão}

Do tripé escolhido para analisarmos o papel e a atuação política do abade de Cluny, a questão do censo pago por Alfonso VI à abadia borgonhesa nos parece aquela que oferece mais desafios. Também, neste caso, enfrentamos dúvidas quanto à fiabilidade do conjunto da documentação, muito embora a carta redigida por Alfonso VI a Hugo de Cluny, provavelmente em 1077 (DAVID, 1947, p. 402-404), e o documento no qual se institui o censo, na mesma data, não apresentem maiores dúvidas (GAMBRA, 1998, doc. 46, 47).

Nessa carta, o monarca declara que se dispóe a entregar anualmente duas mil moedas de ouro sob o conceito de censo a Cluny, dobrando, assim, a quantia que seu pai, Fernando I, pagara em seu reinado. Os motivos que teriam levado Alfonso VI a tamanha generosidade, explicar-se-iam por duas vertentes. Por um lado, de acordo com Bishko, existe uma longa tradição de entregar à igreja uma parte da riqueza arrecadada com os censos das tarifas muçulmanas na Península Ibérica, e no reino de Leão tal prática seria comprovada já com Sancho, el Mayor, e com Fernando I (BISHKO, 1980, p. 4-5). ${ }^{15}$ Assim, Alfonso VI estaria apenas dando continuidade a uma tradição que, ao mesmo tempo, constituía uma espécie de obrigação moral, dada a origem infiel do ouro arrecadado. Em termos do valor do censo, à primeira vista elevado, Bishko argumenta que, devido ao elevado afluxo das parias na época da redação da carta, as quantias não chegam a ser desproporcionais, muito embora tivessem grande impacto em Cluny, a ponto de permitirem a renovação completa e suntuosa da igreja monástica. Porém, no início do reinado, a situação dos cofres régios era bem diferente, o que ajudaria a explicar as doaçóes de mosteiros que o monarca fez à ordem, entre 1073 e 1077, como forma de compensar a falta de liquidez. Por outro lado, não pode passar despercebido que a decisão de duplicar o censo do Pai coincide com a pressão que Gregório VII exerce sobre o monarca para que ele se reconheça vassalo da Santa Sé e adote o rito romano no reino, eliminando o antigo rito hispânico (moçárabe). A disposição de Alfonso VI de dobrar o censo devido a Cluny poderia, então, ser interpretada como uma manobra para eludir a tutela papal, preferindo entrar na esfera de influência do abade de Cluny (BISHKO, 1980, p. 35).

Do ponto de vista das relações que os atores políticos mantinham no reino de Leão, será preciso testar até que ponto é mesmo possível detectar um comportamento constante e de acordo com o que se esperaria de supostos partidários do papado ou de Cluny. $\mathrm{Na}$ verdade, o próprio Gregório VII apelou a Hugo de Cluny para conseguir solucionar alguns problemas que o papado enfrentava no reino de Leão, reconhecendo as capacidades do abade: sed abbas Cluniacensis nos imitando idem faciet; eadem enim via, eodem sensu, eodem spiritu ambulamos (MANSILLA, 1955, p. 33-35). 
A tese que aponta para a decisão de Fernando I em transformar os termos da relação com Cluny de amicitia e de mutuus amor em societas, com a obrigação de pagamento de um censo, que teria vinculado seus sucessores, é rejeitada por alguns autores. Na verdade, a decisão de estreitar os laços nesses termos dever-se-ia unicamente a Alfonso VI, como resultado de um cálculo político em sua relação com o papado. Os termos da carta e do documento em que duplica o censo, referindo-se às obrigações estabelecidas em época de seu pai, seriam apenas fruto da necessidade de dar legitimidade e antiguidade ao vínculo, não passando, portanto de uma falsificação (PICK, 2013; HENRIET, 2017). Tais hipóteses são alimentadas principalmente pelo fato de que não há qualquer documento da época de Fernando I que registre o estabelecimento desse censo. De toda forma, seguindo a Patrick Henriet, nos perguntamos qual seria exatamente a eficácia dessa "proteção cluniacense" contra a demanda de mudança de ritual, que exigisse o pagamento de uma quantia elevada e a criação de laços de dependência formais, em nível de vassalagem (HENRIET, 2017, p. 209). Ainda sobre essa questão, há um documento, de 1090, no qual se registra o juramento de Alfonso VI que renovava a promessa de pagamento do censo dobrado, quando de uma suposta viagem de Hugo a Leão e Castela. Para Julia Montenegro, trata-se de mais um documento falso, elaborado nos scriptoria de Cluny tempos depois (MONTENEGRO, 2009, p. 62).

As respostas não são simples, mas queremos sublinhar uma certa tendência a atribuir ao papado e a Cluny umas capacidades extraordinárias que exigem do historiador a necessidade de explicar as açóes dos atores que se relacionam com eles de acordo com essa premissa. No caso do pagamento do censo a Cluny por Alfonso VI, além dos documentos existentes, cujo tom da linguagem reflete a autoritas e/ou a posição política circunstancial em que o ator se encontra, seria necessário estender a observação a outras manifestações e ações dos integrantes da rede para talvez compreender de que forma esses discursos de poder eram instrumentalizados, flexibilizados ou, até mesmo, se desvaneciam.

\section{Considerações finais}

A título de conclusão, queremos ressaltar que os fatos que escolhemos para apresentar neste artigo são fruto da construção de uma memória que apresenta Hugo de Semur, o abade de Cluny, como absoluto protagonista da expansão de importantes redes borgonhesas e aquitanas no reino de Leão. Sua capacidade de manipular Alfonso VI, quer interferindo nos casamentos régios, quer infiltrando familiares no coração da corte leonesa, dispostos a trair o próprio monarca em favor de Cluny, quer "vendendo" sua proteção ao reino de Leão contra o papado são exemplos significativos de uma narrativa que tende a centrar a interpretação em um só personagem, dando-lhe características heroicas. Ainda que, numa perspectiva nacionalista, as açóes de Hugo de Cluny sejam classificadas como imperialistas, tal tipologia acaba por reverberar positivamente sobre a instituição da igreja, reforçando a ideia do poder extraordinário que seus líderes alcançaram na Idade Média, e que alimenta um imaginário político de longa duração. A sensação é que, apesar de que tal imagem se afaste dos ideais de virtude e de pureza evangélica, o que seria, portanto, passível de condenação, ocorre um efeito contrário, revelador do caráter político da instituição eclesiástica. Esse deslocamento coloca a igreja e seus líderes no centro do poder, construindo a narrativa de um protagonismo institucional incontornável para o processo de civilização do ocidente. Aliás, cabe lembrar que Hugo de Semur foi canonizado em 1120, no pontificado de Calixto II, ${ }^{16}$ 
principalmente por suas capacidades políticas, entendidas, em seu caso, como virtudes. Tal como já apontamos, o que caracteriza a ação de Cluny em Leão, entre a segunda metade do século XI e o início do XII, não é realmente a vida monástica, mas a ação política que a historiografia faz convergir para a cabeça política da ordem. Da mesma forma, embora como seu negativo, a falta de ação de Alfonso VI é bastante perceptível na maneira como os fatos analisados são quase sempre apresentados. $\mathrm{O}$ monarca era tragado pelas dinâmicas que Hugo de Cluny engendrava, tal como ocorria em sua relação com Gregório VII. Entretanto, parece-nos que os três fatos políticos que apresentamos neste trabalho poderão ser vistos de outra maneira se forem analisados à luz das redes que, embora originárias da Borgonha e do Midi, se inseriram, por sua vez, nas redes que já existiam no reino de Leão alargando a geografia de uma teia de interesses, sem fronteiras. ${ }^{17}$

\section{Referências}

ACHERY, Luc d'. Spicilegium sive collectio veterum aliquot scriptorum qui in galliae bibliothecis delituerant. Disponivel em: https://gallica.bnf.fr/ark:/12148/bpt6k108597p/f435.image.r=Prospectus\%20novae\%20 editionis\%20Spicilegium. Acesso em: 31 mar. 2018.

AMARAL, Luís Carlos; BARROCA, Mário Jorge. A condessa-rainha Teresa. 2. ed. Lisboa: Círculo de Leitores, 2016.

ANDRADE, José Miguel. Faint black, brilliant white: from the weakness of Cluny to the strength of the Cistercians (Galicia and Portugal, twelfth and thirteenth centuries). Journal of Medieval Iberian Studies, v. 9, n. 2, 2017.

AZEVEDO, Luís Gonzaga de. História de Portugal. t. III. Lisboa: Biblion, 1942.

BISHKO, Charles Julian. Count Henrique of Portugal, Cluny, and the antecedents of the Pacto Sucessório. Revista Portuguesa de História, t. XIII, 1970.

BISHKO, Charles Julian. Fernand I and the origins of the leonese-castillian alliance with Cluny. Studies in Medieval Spanish Frontier History. Londres: Variorum Reprints, 1980.

BISHKO, Charles Julian. The Cluniac Priories of Galicia and Portugal: their Acquisition and Administration 1075-ca. 1230. Spanish and Portuguese Monastic History 600-1300. Farnham: Ashgate, 1984.

CASTRO, Luís Vieira de. A formação de Portugal. Funchal: Esperança, 1938.

COELHO, Maria Filomena. A jurisdição da aristocracia cristã. Monarquia, nobreza e monacato em Portugal (séculos XII-XIII). Revista Locus, v. 22, n. 1, p. 117-137, 2016.

COELHO, Maria Filomena. Um universo plural: política e poderes públicos na Idade Média (séc. XII-XIII). In: TORRES FAUAZ, Armando (ed.). La Edad Media em perspectiva latino-americana. Heredia: Ed. Universidad Nacional de Costa Rica, 2018. p. 133-150.

COSTA, Avelino J. da. A Ordem de Cluny em Portugal. Braga: Cenáculo, 1948.

DAVID, Pierre. Grégoire VII, Cluny et Alphonse VI. In: DAVID, Pierre. Etudes Historiques sur la Galice et le Portugal. Du V|ème au XIİ̀me siècle. Coimbra: Portugália, 1947.

DAVID, Pierre. Le pacte susscessoral entre Raymond de Galice et Henri de Portugal. Bulletin Hispanique, t. L, n. 3-4, p. 277, 1948.

DEFOURNEAUX, Marcelin. Les français en Españe au Xième et XIlème siècles. Paris: PUF, 1949.

ESTEFÂNIO, Abel. O pacto sucessório revisitado: o texto e o contexto. Medievalista, n. 10, 2011.

ESTEFÂNIO, Abel. Proposta de aclaração do "pacto sucessório" à luz de novos dados. Medievalista, n. 16, p. 1-33, 2014

GAMBRA, Andrés. Alfonso VI. Cancillería, curia e imperio. León: Centro de Estudios e Investigación San Isidoro, 1998. (Colección Fuentes y Estudios de Historia Leonesa, 63). 
HENRIET, Patrick. Moines envahisseurs ou moines civilisateurs? Cluny dans l'historiographie espagnole (XII-XIII siècles). Revue Mabillon, v. 11, p. 135-159, 2000.

HENRIET, Patrick. Cluny and Spain before Alfonso VI: remarks and propositions. Journal of Medieval Iberian Studies, v. 9, p. 206-219, 2017.

MANSILLA, Demetrio. La documentación pontifícia hasta Inocencio III. Roma: Instituto Español de Estudios Eclesiasticos, 1955.

MARQUES, A. H. de Oliveira. O poder e o espaço. In: SERRÃO, Joel; MARQUES, A. H. de Oliveira (dir.). Portugal em definição de fronteiras. Lisboa: Presença, 1996. (Coleção Nova História de Portugal, v. III).

MONTENEGRO, Julia. La alianza de Alfonso VI con Cluny y la abolición del rito mozárabe en los reinos de León y Castilla: una nueva valoración. lacobus, n. 25-26, p. 62, 2009.

PÉREZ DE URBEL, Justo. Año Cristiano. Burgos: Aldecoa, 1935. v. II.

PICK, Lucy. Rithinking Cluny in Spain. Journal of Medieval Iberian Studies, v. 5, p. 1-17, 2013.

REGLERO DE LA FUENTE, Carlos. Cluny en España. Los prioratos de la provincia y sus redes sociales (1073-ca. 1270). León: Centro de Estudios e Investigación San Isidoro, 2008. (Coleção Fuentes y Estudio de Historia Leonesa, 122).

RUCQUOI, Adeline. Cluny, el Camino Francés y la Reforma Gregoriana. Medievalismo, Espanha, n. 20, p. 97-22, 2010.

SAINT-JEAN VITUS, Benjamin. Tournus, le castrum, l'abbaye, la ville, XIe-XIVe siècles et prémices. Tese (Doutorado em História da Arte) - Université Lumière de Lyon, Lyon, 2006. Disponível em: http://theses.univ-lyon2. fr/documents/lyon2/2006/saint-jeanvitus_b. Acesso em: 20 jun. 2018.

SALAZAR Y ACHA, Jaime de. Contribución al estudio del reinado de Alfonso VI de Castilla: algunas aclaraciones sobre su política matrimonial. Anales de la Real Academia Matritense de Heráldica y Genealogía, p. 299-335, 1992-1993.

SÁNCHEZ-ALBORNOZ, Claudio. España un enigma histórico. v. II. Buenos Aires: Sudamericana, 1962.

SENRA, José Luis. Tournus et Sahagún: une connexion architecturale et institutionnelle à la fin du xI ${ }^{\circledR}$ siècle? Bulletin du Centre d'Études Médiévales d'Auxerre (BUCEMA), n. 15, 2011. Disponível em: http://journals.openedition.org/cem/12103. Acesso em: 23 set. 2018.

\section{Notas}

${ }^{1}$ Nas palavras de Pierre David, “[...] les Clunisiens ont été appelés avant tout, par les rois et les évêques, pour propager une discipline spirituelle qui faisait ses preuves depuis le début du Xème siècle" (DAVID, 1947, p. 363). Há uma tendência a interpretar a relação entre a monarquia navarro-basca e Cluny, quer como uma autêntica vassalagem feudal, quer como traição à nação, ou ainda como tentativa de “aggiornamento” da civilização perdida (BISHKO, 1980, p. 2).

${ }^{2} \mathrm{Na}$ opinião de Charles Bishko, os entreditos que alguns eruditos lançam sobre a documentação, devido aos fortes indícios de falsificação e de interpolação são normalmente ignorados pelos historiadores, que assumem as informações contidas nos documentos. Erros perpetuados, segundo diferentes agendas, por “francófilos, xenófobos e cidólatras" (BISHKO, 1980, p. 2-3)

${ }^{3}$ Com relação às datas que adotaremos neste trabalho, relembramos que há dúvidas entre os estudiosos com relação a boa parte dos acontecimentos que envolvem os registros e, portanto, a depender do historiador pode haver discordâncias que chegam à dezena de anos. Tentaremos adotar uma cronologia de acordo aos estudos mais recentes.

${ }^{4}$ Entretanto, para alguns autores, o Caminho foi aberto muito antes da chegada de Cluny à Península (RUCQUOI, 2010).

5 “When we eventually possess a trustworthy geography of the Luso-Hispanic priories, subpriories, patrimonies and cotos, it is bound to become even more apparent than it is at present that the great majority of these lay in three principal areas the Rioja Alta, the Tierra de Campos (i.e., the diocese of Palencia) and the Galaico-Portuguese West. The reasons for this neglected but unmistakable pattern of Cluniac territorial concentration in medieval Iberia have yet to be seriously investigated; but in the first two instances it is reasonably clear that they derive in large part from the intimate alliance forged between Cluny and the Leonese Empire of Hispania under the king-emperors Fernando I and Alfonso VI" (BISHKO, 1984). 
6 "The arrival of the Rule of Saint Benedict in Galicia and Portugal was a late and complex phenomenon. Prior to the last thirty years of the eleventh century there were no monasteries that adhered fully to the Rule of Saint Benedict, and the spread of the influence of the Abbey of Monte Cassino was neither uniform nor immediate. This pre-existing situation affected, from the outset, how Cluny became established in these two territories".

7 "This viewpoint saw the change in liturgical rites and the pretensions of the Gregorian reform itself, the handwriting system, the arrival of the Romanesque and the emergence of a true French pilgrimage route to Compostela as changes imported and implanted by the French. It also imagined the all-embracing influence of Cluny as the prime mover for all of these transformations".

${ }^{8}$ Ainda para aqueles cenóbios que formalmente estabeleceram vínculos com Cluny, seria necessário entender até que ponto os velhos hábitos foram substituídos pelas diretrizes cluniacenses. No caso do mosteiro de Jubia, por exemplo, José Andrade suspeita que quase nada mudou (ANDRADE, 2017, p. 235). Embora haja tendência a pensar que no caso dos processos de reforma ocorridos posteriormente sob a égide cisterciense tenha sido diferente, cremos que talvez tampouco haja grandes mudanças (COELHO, 2016, p. 117-137).

${ }^{9}$ De acordo com Oliveira Marques, depois da derrota de Zalaca (Sagrajas), em 1086, Alfonso VI pediu ajuda aos franceses; um exército comandado pelo duque da Borgonha, Eudes I (sobrinho de Constança), de seu irmão Roberto, do conde de Toulouse, Raimundo de Saint Gilles, de Hugo de Lusignan, atravessou os Pirineus, em 1087, mas a missão foi um fracasso (MARQUES, 1996, p. 15)

${ }^{10}$ Luís Carlos Amaral e Mário Barroca, ao traçar a genealogia dos dois personagens, afirmam que Henrique e Raimundo tinham trisavós comuns, os respectivos bisavôs eram irmãos e os avós eram primos direitos.

${ }^{11}$ Domino atque Reuerētissimo Cluniacēsi Abbati HVGONI, omníque Beati Petri Congregationi, RAIMVNDVS Comes eiúsque filius, \& HENRICVS Comes eius familiaris, cum dilectione salutem in Christo. Sciatis, Carissime Pater, quòd postquàm vestrum vidimus legatum pro Dei omnipotentis atque Beati Petri Apostoli timore vestræque dignitatis reuerentia quod nobis mandastis in manu Domni Dalmatij Geret fecimus.

${ }^{12}$ Saint Huges, cependant, estimait à juste titre que les intérêts de la chrétienté en Espagne pourraient être gravemente compromis si Henri et Raymond n'agissaient point en plein accord.

${ }^{13}$ Sobre o suposto juramento de Afonso VI a Raimundo: "Reimundus... quem rex Adefonsus a Burgundia in Hispaniam venire fecerat et cui totum suum regnum jurejurando policitus fuerat." Petite Chronique de Compostelle, écrite vers 1130 , España Sagrada, t. XX, p. 611 (apud DAVID, 1948, p. 278, nota 1).

${ }^{14}$ Ressalve-se que Abel Estefânio encontrou a transcrição manuscrita na Recueil des Chartes de Cluny, e não a carta original (ESTEFÂNIO, 2014, p. 29).

${ }^{15}$ Para Bishko, entretanto, os presentes que Sancho envia a Cluny, oriundos sobretudo dos espólios muçulmanos, não podem ser interpretados como a origem de um pagamento de subordinação ou, até mesmo, como a evidência do envolvimento de Cluny no planejamento da Reconquista, como a cruzada. As ligações de Sancho com Cluny eram sobretudo de caráter pessoal e piedoso, e não permitem ser estendidas a seus herdeiros como obrigação vinculante.

${ }^{16}$ Calixto Il era irmão de Raimundo da Borgonha.

${ }^{17}$ Pretendemos seguir nessa direção no próximo trabalho.

Data de recebimento: $16 / 11 / 2018$

Data de aprovação: 27/04/2019 